\title{
Systematic Review: Telemedicine dalam Manajemen Pasien Gagal Jantung semasa Pandemi
}

\author{
Sidhi Laksono슬 Anhari Achadi², Reynaldo Halomoan ${ }^{3}$ \\ 1,2Fakultas Kesehatan Masyarakat, Universitas Indonesia \\ ${ }^{3}$ Fakultas Kedokteran dan Ilmu Kesehatan, Universitas Katolik Indonesia Atma Jaya \\ sidhilaksono@uhamka.ac.id ${ }^{1}$
}

Diajukan 17 Desember 2020 Diperbaiki 9 Februari 2021 Diterima 15 Februari 2021

\section{ABSTRAK}

Latar Belakang: Pandemi global COVID-19 menjadi hambatan bagi kunjungan pasien gagal jantung ke rumah sakit. Untuk itu, telemedicine yang memanfaatkan teknologi dan dapat mengurangi kontak fisik antara dokter dengan pasien dapat menjadi solusi bagi manajemen pasien. Telemedicine juga memiliki potensi untuk memberikan keluaran yang baik bagi pasien.

Tujuan: Mengevaluasi dampak telemedicine dalam perawatan pasien gagal jantung.

Metode: Pencarian komprehensif menggunakan kata kunci dilakukan dari 2 basis data selama tahun 2000-2020 untuk mengidentifikasi studi mengenai penerapan telemedicine pada manajemen pasien gagal jantung. Setelah itu, dilakukan penilaian risiko bias dan ekstraksi data.

Hasil: Terdapat 2 uji coba terkontrol secara acak dan 2 studi kohort prospektif yang dikaji. Tiga studi menunjukkan penurunan laju hospitalisasi pada pasien gagal jantung. Untuk mortalitas, 1 studi menunjukkan penurunan yang bermakna pada kelompok pasien gagal jantung yang menjalani telemedicine. Namun, pada 1 studi lain tidak terdapat perbedaan bermakna (semua penyebab kematian). Terdapat 1 studi masing-masing yang membahas mengenai kualitas hidup dan kepatuhan berobat, dan terdapat perbedaan bermakna, sedangkan untuk biaya, 1 studi menunjukkan penurunan biaya yang dikeluarkan dan 1 studi tidak menunjukkan perbedaan bermakna.

Kesimpulan: Telemedicine memberikan manfaat terhadap keluaran pasien gagal jantung.

Kata Kunci: telemedicine; pasien gagal jantung; keluaran pasien

\section{ABSTRACT}

Background: The global pandemic COVID-19 is an obstacle to hospital visits for heart failure patients. Therefore, telemedicine that utilizes technology and reduces physical contact becomes a solution for patient management. Telemedicine is also potential to provide good outcomes.

Objective: Evaluate the impact of telemedicine in the treatment of heart failure patients.

Method: A comprehensive keyword search was performed from 2 databases from 2000-2020 to identify studies regarding the application of telemedicine in the management of heart failure patients. After that, a risk of bias assessment and data extraction were carried out.

Results: There were 2 randomized controlled trials and 2 prospective cohort studies. Three studies showed a reduction in the rate of hospitalization in heart failure patients. 1 study showed a significant mortality reduction in the group of heart failure patients undergoing telemedicine. However, in other stud ies there was no significant difference (all causes of death). One study showed a significant difference in the quality of life and treatment adherence. As for costs, 1 study showed a reduction in costs and 1 study did not show a significant difference.

Conclusion: Telemedicine provides benefits to the outcome of heart failure patients.

Keywords: telemedicine; heart failure patients; patient outcomes 
PENDAHULUAN

Gagal jantung merupakan manifestasi yang sering terjadi pada penyakit jantung dengan prevalensi yang meningkat, terutama berkaitan dengan proses penuaan serta membutuhkan manajemen jangka panjang dan pemantauan terapi secara rutin (Savarese \& Lund, 2017). Namun, pandemi global COVID-19 menyebabkan gangguan pelayanan kesehatan terhadap pasien berupa penurunan jumlah kunjungan pasien gagal jantung. Keadaan ini juga mendorong penyesuaian dalam pengaturan sistem rumah sakit termasuk aktivitas departemen kardiologi (De Simone et al., 2020).

Telemedicine menjadi alternatif potensial untuk tetap memberikan pelayanan kesehatan pasien dengan meminimalisir risiko paparan dan kontak fisik. Telemedicine yang digunakan seperti telepon, telepon pintar, serta perangkat nirkabel seluler merupakan media pendukung diagnosis dan pemberian terapi (Gensini et al., 2017). Efektivitas telemedicine dalam manajemen gagal jantung telah dinilai dalam studi oleh Savard et al. (2011) dan menunjukkan hasil yang baik berupa penurunan 34\% semua penyebab mortalitas dan 30-56\% hospitalisasi akibat gagal jantung.

Penelitian oleh Dendale et al. (2012) juga menunjukkan hasil yang sama dimana terdapat penurunan mortalitas, hospitalisasi, serta jumlah hari yang hilang karena perawatan. Studi metaanalisis ini juga menunjukkan kemungkinan bahwa manfaat telemedicine dapat dirasakan pada periode tindak lanjut yang lebih lama ( $>6$ bulan). Kajian sistematis ini bertujuan untuk melihat manfaat penerapan telemedicine dalam manajemen pasien gagal jantung untuk meningkatkan keluaran pasien. pedoman PRISMA (Preferred Reporting Items for Systematic Reviews and MetaAnalysis). Pencarian dilakukan melalui Pubmed dan Cochrane Library terhadap artikel bahasa Inggris sejak tahun 20002020.

Dari pencarian tersebut didapatkan 33 artikel yang sesuai. Studi yang memenuhi syarat adalah uji coba terkontrol secara acak dan studi observasional prospektif tentang peran telemedicine/telecardiology pada pelayanan kesehatan pasien gagal jantung dari rumah. Studi kajian sistematis dan metaanalisis, tinjauan pustaka, studi retrospektif, non-intervensi, durasi kurang dari 6 bulan, protokol, dan studi bukan tentang gagal jantung akan dieksklusi. Strategi pencarian dilakukan dengan memasukkan kata kunci: telemedicine AND telecardiology AND heart failure patients AND hospital.

\section{Seleksi Studi dan Ekstraksi Data}

Artikel duplikasi akan dihapus. Setelah itu, artikel yang berpotensi akan di screening melalui judul dan abstrak untuk mencari sumber yang relevan. Teks lengkap dari artikel yang sesuai kemudian diulas dan dinilai berdasarkan kriteria inklusi dan eksklusi.

Tabel 1. Metode PICO (Population, Intervention, Comparison, Outcome)

\begin{tabular}{ccl}
\hline No & \multicolumn{1}{c}{ PICO } & \multicolumn{1}{c}{ Keterangan } \\
\hline 1 & Population & Pasien dengan gagal jantung \\
2 Intervention & $\begin{array}{l}\text { Perawatan terhadap pasien } \\
\text { dengan menggunakan } \\
\text { teknologi yang mendukung } \\
\text { pelaksanaan telemedicine }\end{array}$ \\
3 Comparison & $\begin{array}{l}\text { Perawatan standar } \\
4 \text { Outcome }\end{array}$ & $\begin{array}{l}\text { Tingkat mortalitas, re- } \\
\text { hospitalisasi, kualitas hidup, } \\
\text { kepatuhan penggunaan obat, } \\
\text { biaya }\end{array}$ \\
&
\end{tabular}

\section{METODE}

\section{Strategi pencarian}

Kajian sistematis ini mengikuti 


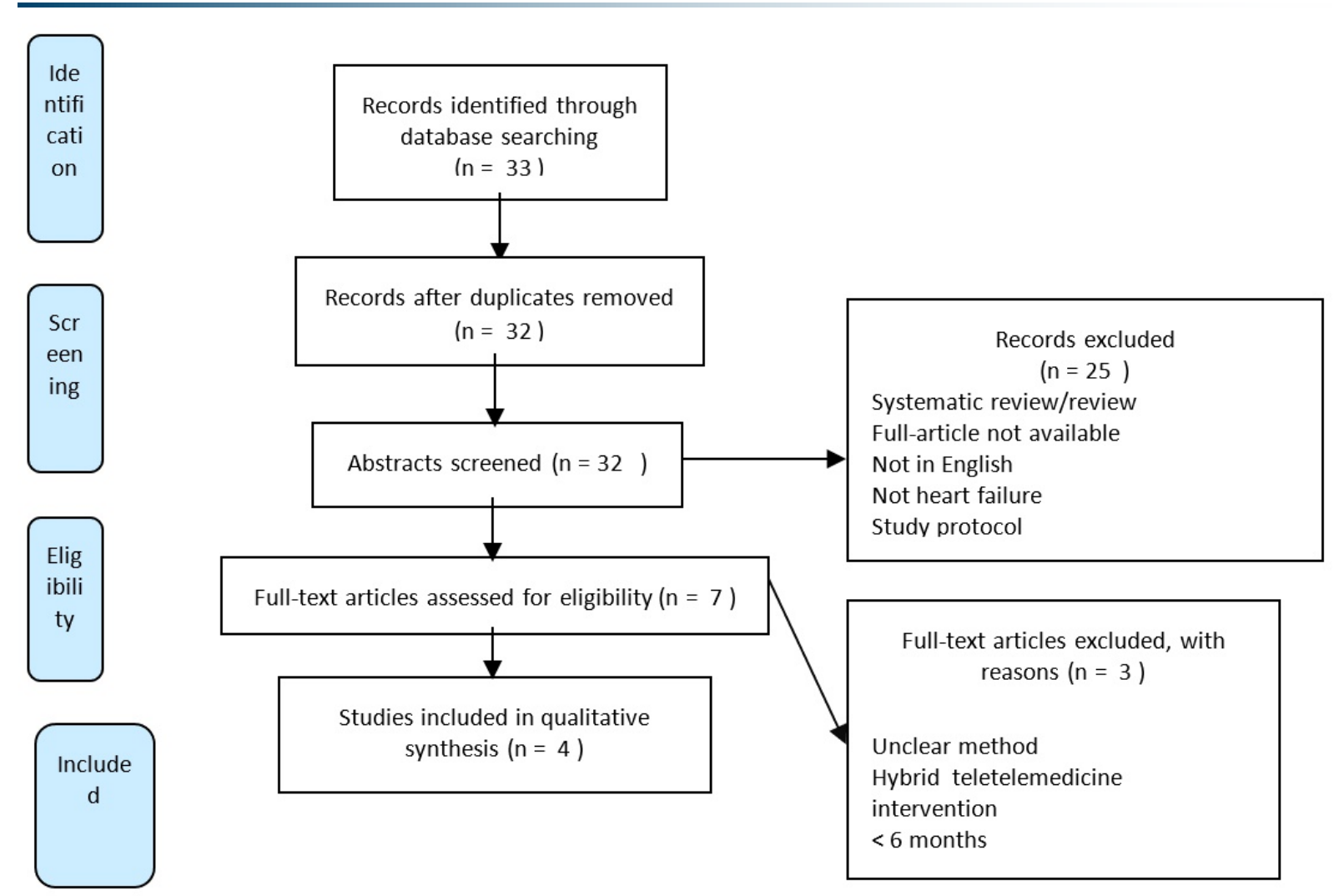

\section{Gambar 1. Bagan Alur Seleksi Studi Menurut Pedoman PRISMA}

\section{Penilaian kualitas studi}

Studi yang memenuhi kriteria inklusi akan dinilai untuk menentukan adanya risiko bias. Studi RCT akan dinilai menggunakan Cochrane risk of bias tool (Higgins \& Altman, 2008), sedangkan untuk studi non RCT akan dinilai dengan menggunakan Skala Newcastle-Ottawa (Kotb et al., 2015).

\section{HASIL DAN PEMBAHASAN}

Pada pencarian awal ditemukan total 33 studi. Setelah mengeksklusi studi yang sama dari 2 basis data, penilaian melalui abstrak, dan penilaian isi keseluruhan artikel, terdapat 4 studi yang dapat diinklusikan ke dalam kajian ini. Dua studi merupakan studi kohort yang merupakan studi kohort prospektif. Dua studi lainnya merupakan uji coba terkontrol secara acak yang membandingkan intervensi dengan telemedicine dan kelompok penanganan gagal jantung yang standar.

Kedua studi kohort ini dilakukan dengan memberikan alat untuk memantau kondisi pasien dari rumah yang dapat mengirimkan data ke komputer pusat (Riley et al., 2015). Kedua studi ini menunjukkan bahwa telemedicine dapat menjadi alternatif dalam manajemen pasien karena berhasil mengurangi tingkat hospitalisasi pasien gagal jantung serta menurunkan jumlah hari rawat pasien.

Studi oleh Riley et al. (2015) menunjukkan bahwa penurunan jumlah hospitalisasi sebesar $42 \%$ dalam jangka waktu 6 bulan. Penurunan jumlah hospitalisasi juga ditunjukkan oleh Roth et al., (2004) yang mengkategorikan hal tersebut berdasarkan derajat gagal jantung dari Klasifikasi fungsional Asosiasi Jantung New York. Penurunan paling banyak terjadi pada kelompok kelas II dan kelas III sebesar $82 \%$ dan $75 \%$ masing-masing, sedangkan untuk kelompok pasien kelas IV mengalami penurunan sebesar 57\% (Roth et al., 2004). 
1 Program Evaluation of Riley et al. Remote Heart Failure (2015) Monitoring: Healthcare Utilization Analysis in a Rural Regional Medical Centera

pemantauan nirkabel jarak broadband seluler selama 6 bulan jauh dengan broadband Alat ini mengukur denyut jantung, tekanan seluler untuk memfasilitasi darah, berat badan, dan Saturasi dan data pasien di daerah pedesaan dikirim secara mobile. dan tim manajemen gagal jantung.

2 Telecardiology for Roth et al. Menilai efek pemantauan Pasien akan mengukur laju jantung, tekanan patients with chronic (2004) heart failure: the SHL experience in Israel dan tindak lanjut trans darah, dan berat badan setiap hari. Data telepon pada laju admisi pemeriksaan akan dikirimkan secara rumah sakit dan durasi otomatis ke pusat data. Pasien akan mengisi perawata
hidup

3 Long-term impact of a Frederix Untuk menilai apakah Awalnya, 160 pasien diacak ke dalam a. Semua penyebab kematian tidak six-month telemedical et care programme on (2019) mortality, hf readmissions, and healthcare cost in $\mathrm{CHF}$ patients al. telemonitoring

ama 6 kelompok

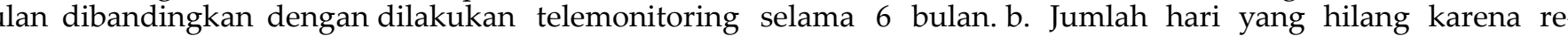
perawatan biasa dapat Pasien kelompok telemonitoring akan admisi lebih rendah pada grup mengurangi mortalitas, re- mengukur berat badan, tekanan darah, dan telemonitoring.

admisi, dan biaya perawatan laju jantung sesuai protokol dan data akan c. Durasi tindak lanjut lebih rendah kesehatan. dikirimkan ke pusat data. Setelah 6 bulan, terdapat 142 pasien yang akan menjalani d. Ju pemantauan jangka panjang selama 79 pada kelompok telemonitoring. ( Penurunan jumlah biaya. Program pemantauan gagal jantung jarak jauh dapat diaplikasikan pada daerah rural.

Penurunan jumlah hospitalisasi, penurunan jumlah hari perawatan, 91\% responden mengalami perbaikan pada kualitas hidup. bulan.

umlah hari yang hilang karena readmisi semua penyebab tidak berbeda.

e. Biaya perawatan kesehatan tidak berbeda secara signifikan. Namun, biaya pada kelompok telemonitoring lebih rendah.

4 Impact of home patient Antonicell Untuk menilai dampak 57 subjek dikelompokkan secara acak ke a. Peningkatan penggunaan obat

terhadap kelompok telemonitoring dan kontrol dan penghambat beda, statin, dan beta blocker in (2010) congestive heart failure

\section{at.} penurunan mortalitas, dan kelompok telemonitoring akan dihubungi b. laju re-admisi. setidaknya 1 kali seminggu untuk mendapatkan informasi mengenai gejala, jantung, berat badan, dan keluaran urin 24 jam. penghambat beda, statin, dan antagonis reseptor mineralokortikoid. Kombinasi mortalitas dan re-admisi lebih rendah pada kelompok telemonitoring. 
Durasi perawatan pada kedua studi juga mengalami penurunan lebih dari $60 \%$, yaitu sebesar $64 \%$ (14.2 hari menjadi 5.2 hari) dan sebesar 78\% (13.75 hari menjadi 3.06 hari) (Riley et al., 2015; Roth et al., 2004). Biaya perawatan berdasarkan hasil penelitian Riley et al. (2015) mengalami penurunan, dimana terdapat penurunan sebesar $67 \%$ ( $\$ 138,000$ menjadi $\$ 44,673)$.

Peningkatan kualitas hidup pasien dievaluasi melalui studi oleh Roth et al. (2004), dengan aspek yang dinilai setiap bulan ke 4, 8, dan 12. Jumlah responden yang mengalami peningkatan kualitas hidup semakin bertambah dalam setiap evaluasi, yaitu sebesar $50 \%$ pada bulan ke4, $71 \%$ pada bulan ke-8, dan $91 \%$ pada bulan ke-12.

Penerapan telemedicine pada studi oleh Riley et al. (2015) juga menunjukkan bahwa pasien mengeluarkan biaya perawatan yang lebih rendah, yaitu sebesar $67 \%$. Studi ini juga secara khusus meneliti peran telemedicine pada pasien di area pedesaan (rural).

Pada uji coba terkontrol terdapat dua studi uji coba secara acak pada kajian ini. Partisipan diacak ke dalam kelompok yang mendapatkan telemonitoring dan kelompok yang mendapatkan perawatan standar. Periode tindak lanjut adalah 6 bulan dan 12 bulan untuk studi oleh Frederix dan Antonicelli masing-masing (Antonicelli et al., 2010; Frederix et al., 2019).

Kedua studi dilakukan pada pasien dengan diagnosis gagal jantung. Partisipan yang terlibat berumur lebih dari 70 tahun $(76 \pm 10$ tahun dan $78.2 \pm 7.3$ tahun pada studi oleh Frederix dan Antonicelli masing-masing) dan populasi laki-laki lebih banyak dibandingkan dengan populasi wanita.

Frederix et al. (2019) membandingkan kelompok pasien yang mendapatkan tindak lanjut melalui telemonitoring (TM) dengan kelompok pasien yang mendapatkan perawatan standar atau biasa. Pada kelompok TM, pasien diminta untuk mengukur berat badan, tekanan darah, dan denyut jantung dengan perangkat elektronik yang akan mengirimkan data secara otomatis ke komputer pusat.

Jika terdapat abnormalitas pada hasil pengukuran, tenaga kesehatan akan mendapatkan tanda peringatan melalui surat elektronik. Dokter akan melakukan kunjungan untuk memberikan penyesuaian terapi dan pasien akan dihubungi 1-3 hari kemudian melalui telepon untuk mengevaluasi efektivitas terapi. Setelah fase 6 bulan tindak lanjut dengan TM selesai, pasien akan ditindaklanjuti dengan perawatan standar (Frederix et al., 2019).

Studi oleh Antonicelli et al. (2010) membandingkan aplikasi TM dengan perawatan standar. Kelompok pasien TM akan dihubungi dengan telepon oleh tim perawatan gagal jantung untuk mengevaluasi gejala, tekanan darah, denyut jantung, berat badan, keluaran urin, dan kepatuhan dalam konsumsi obat. Pasien juga akan mendapatkan evaluasi elektrokardiografi setiap minggu.

Hasil pemeriksaan tersebut akan menentukan perlu atau tidaknya modifikasi terapi pada pasien. Titik akhir studi primer adalah kombinasi laju mortalitas dan re-hospitalisasi karena gagal jantung, sedangkan itik akhir sekunder adalah laju mortalitas dan rehospitalisasi secara terpisah (Antonicelli et al., 2010).

Frederix et al. (2019) menunjukkan bahwa keluaran primer (semua penyebab kematian) tidak berbeda secara signifikan antara kelompok TM dengan kelompok kontrol $(p=0.61)$. Jumlah hari yang hilang karena re-hospitalisasi akibat semua penyebab juga tidak berbeda secara bermakna. Namun, studi ini menunjukkan bahwa telemonitoring memberikan manfaat pada keluaran sekunder yang khusus berkaitan dengan 
gagal jantung.

Kelompok pasien TM mengalami penurunan signifikan $(p=0.04)$ terhadap jumlah hari yang hilang karena rehospitalisasi akibat gagal jantung $(7.28 \pm$ 12.55 hari) dibandingkan dengan kelompok kontrol (11.81 \pm 18.57 hari). Waktu yang dibutuhkan untuk tindak lanjut di rumah sakit juga lebih rendah pada kelompok TM (Frederix et al., 2019).

Frederix et al. (2019) lebih spesifik menunjukkan bahwa telemonitoring memberikan manfaat terhadap pasien gagal jantung dengan usia $\geq 75$ tahun, mengurangi frekuensi re-admisi pada pasien dengan ejeksi fraksi $\geq 35 \%$, dan penurunan mortalitas pada pasien dengan ejeksi fraksi < 35\%. Studi ini juga membandingkan biaya yang perlu dikeluarkan oleh pasien.

Meskipun tidak terdapat perbedaan yang signifikan antara kelompok TM dengan kontrol, total biaya yang perlu dikeluarkan pada kelompok TM lebih rendah (Frederix et al., 2019). Lebih jauh, studi oleh Frederix et al. 2019 adalah satusatunya studi yang melihat efek jangka panjang dari pelaksanaan telemedicine.

Pada studi oleh Antonicelli et al. (2010) secara khusus diteliti mengenai kepatuhan konsumsi obat yang diresepkan antara kelompok TM dengan kontrol di mana pasien pada kelompok TM memiliki kepatuhan sebesar 89.7\% dibandingkan dengan kelompok kontrol yang hanya sebesar $35.7 \%$ ( $p<0.03)$.

Hal lain yang dianalisis adalah kombinasi antara mortalitas dan rehospitalisasi antar kelompok. Kelompok pasien TM memiliki gabungan tingkat mortalitas dan re-hospitalisasi yang lebih rendah dibandingkan dengan kelompok kontrol ( $\mathrm{p}<0.01)$ (Antonicelli et al., 2010).

Dalam kajian sistematis ini, masingmasing 4 studi memiliki beberapa perbedaan, tetapi seluruhnya dapat menunjukkan bahwa peran telemedicine dalam manajemen pasien gagal jantung dapat menjadi pilihan yang patut dipertimbangkan, terutama dalam kondisi yang menyulitkan terjadinya prosedur manajemen tatap muka antara pasien dengan tenaga medis. Konsep telemedicine bertujuan untuk meningkatkan kondisi pasien serta mengurangi biaya perawatan pada pelayanan kesehatan konvensional.

Sebuah meta-analisis pada berbagai uji coba terkontrol secara acak terhadap 10.193 pasien oleh Kotb et al. (2015) menunjukkan bahwa penggunaan beberapa jenis telemedicine (telemonitoring, via telepon), berhasil menurunkan tingkat mortalitas dan hospitalisasi secara signifikan apabila dibandingkan dengan perawatan biasa. Studi ini juga menunjukkan intervensi telemedicine yang melibatkan transmisi data elektrokardiografi dapat mengurangi hospitalisasi akibat gagal jantung (Kotb et al., 2015).

Manajemen pasien tanpa pertemuan tatap muka dengan teknologi telemedicine tentu diharapkan memberikan dampak positif, salah satunya adalah mengurangi durasi perawatan pada pasien yang perlu dirawat di rumah sakit. Dalam kajian ini, studi dari Riley et al. (2015) dan Roth et al. (2004) membahas terdapat penurunan jumlah hari perawatan pasien di rumah sakit.

Hal ini juga sesuai dengan sebuah meta-analisis oleh Zhu et al. (2020) yang menunjukkan terdapat perbedaan signifikan terhadap durasi perawatan antara kelompok pasien gagal jantung yang mendapatkan intervensi telemedicine dengan kelompok perawatan standar. Hasil ini dapat menjadi alasan bahwa penerapan telemedicine aman dan efektif dalam memperbaiki kondisi pasien tanpa perlu melakukan kunjungan tatap muka ke rumah sakit.

Kepatuhan pada konsumsi obat yang diresepkan memegang peranan penting dalam menghasilkan keluaran yang baik pada pasien. Ramaekers et al. (2009) dalam studinya juga menunjukkan bahwa peningkatan kualitas hidup pasien 
yang menggunakan layanan telemedicine, terutama dipengaruhi oleh kepatuhan terapi farmakologis dan juga nonfarmakologis. Kepatuhan pasien dalam terapi juga dapat mengurangi total biaya yang dikeluarkan untuk pelayanan kesehatan serta mengurangi hospitalisasi (Ramaekers et al., 2009).

Dalam kajian kami, terdapat 1 studi yakni dari Antonicelli et al. (2010) yang melihat dampak telemedicine terhadap kepatuhan pasien dalam terapi. Terdapat peningkatan yang signifikan terhadap penggunaan obat penghambat beta, statin, dan antagonis reseptor mineralokortikoid. Selain itu, telemedicine dapat digunakan untuk melakukan titrasi dosis obat.

Hal ini ditunjukkan oleh Spaeder et al. (2006) dimana titrasi obat carvedilol berhasil dilakukan pada pasien gagal jantung. Hal ini memberikan pemahaman bahwa telemedicine tidak hanya dapat digunakan untuk mengumpulkan data saja tetapi juga berguna bagi tenaga kesehatan untuk administrasi obat pada pasien gagal jantung.

Studi-studi mengenai telemedicine lebih sedikit membahas mengenai kualitas hidup pasien. Padahal, peningkatan kualitas hidup menjadi salah satu parameter bahwa suatu manajemen bekerja dengan baik. Pada kajian kami, hanya ada 1 studi yang membahas mengenai perubahan kualitas hidup pada pasien yang mendapatkan manajemen dengan telemedicine. Selama 3 kali evaluasi per 4 bulan, terjadi peningkatan jumlah responden yang melaporkan peningkatan kualitas hidup (Roth et al., 2004).

Sebuah studi meta-analisis oleh Knox et al. (2017) mencoba melihat pengaruh telemedicine terhadap kualitas hidup aspek fisik, mental, dan keseluruhan. Analisis terpisah terhadap kesehatan mental dan fisik tidak menunjukkan peran telemedicine yang signifikan dibandingkan dengan perawatan standar.

Namun, terdapat peningkatan kualitas hidup keseluruhan pada kelompok telemedicine dalam manajemen pasien gagal jantung. Studi lebih lanjut diperlukan untuk memahami dampak telemedicine terhadap kualitas hidup pasien (Knox et al., 2017).

Kelebihan telemedicine yaitu dapat mengurangi biaya yang dikeluarkan oleh pasien (Gensini et al., 2017). Studi mengenai aspek biaya memberikan hasil yang pro dan kontra.

Kajian kami terdapat 2 studi yang membahas biaya pada penerapan telemedicine (Frederix et al., 2019; Riley et al., 2015). Dari kedua studi ini, hanya Riley et al. (2015) yang menunjukkan penurunan biaya yang signifikan pada pelaksanaan telemedicine, sedangkan studi oleh Frederix et al. (2019) tidak memberikan perbedaan yang signifikan antara kelompok telemedicine dan kelompok kontrol meski biaya yang dikeluarkan pada kelompok TM lebih rendah.

Menurut Comín-Colet et al. (2016), terdapat penurunan biaya yang signifikan setelah 6 bulan pada pasien yang menjalani telemedicine, sedangkan studi oleh Blum \& Gottlieb (2014) menyatakan bahwa telemonitoring tidak mengurangi biaya yang dikeluarkan. Oleh karena heterogenitas hasil studi yang membahas tentang biaya pada penerapan telemedicine dibandingkan dengan perawatan biasa, masih belum dapat disimpulkan telemedicine dapat mengurangi biaya secara keseluruhan.

Telemedicine memberikan suatu langkah baru dalam dunia medis. Namun, penerapannya tidak lepas dari adanya batasan. Salah satu yang menjadi perhatian adalah kualitas pelayanan dan hubungan antara dokter dengan pasien. Batasan-batasan lain juga berupa preferensi pasien, kesulitan menggunakan teknologi, gangguan teknis, privasi data, serta kurangnya peraturan pendukung (Greenhalgh et al., 2017). 
PENUTUP

Telemedicine memberikan manfaat bagi manajemen pasien gagal jantung dengan menurunkan tingkat rehospitalisasi. Selain itu, telemedicine juga dapat menurunkan mortalitas, meningkatkan kualitas hidup, menurunkan biaya perawatan, dan meningkatkan kepatuhan konsumsi obat. Namun, data mengenai hal ini masih terbatas dan studi lebih lanjut diperlukan untuk meneliti dampak telemedicine terhadap keluaran tersebut.

\section{DAFTAR PUSTAKA}

Antonicelli, R., Mazzanti, I., Abbatecola, A. M., \& Parati, G. (2010). Impact of Home Patient Telemonitoring on Use of $\beta$-Blockers in Congestive Heart Failure. Drugs \& Aging, 27(10), 801805. https://doi.org/10.2165/11538210000000000-00000

Blum, K., \& Gottlieb, S. S. (2014). The Effect of a Randomized Trial of Home Telemonitoring on Medical Costs, 30Day Readmissions, Mortality, and Health-Related Quality of Life in a Cohort of Community-Dwelling Heart Failure Patients. Journal of Cardiac Failure, 20(7), 513-521. https:// doi.org/10.1016/j.cardfail.2014.04.016

Comín-Colet, J., Enjuanes, C., VerdúRotellar, J. M., Linas, A., RuizRodriguez, P., González-Robledo, G., Farré, N., Moliner-Borja, P., RuizBustillo, S., \& Bruguera, J. (2016). Impact on clinical events and healthcare costs of adding telemedicine to multidisciplinary disease management programmes for heart failure: Results of a randomized controlled trial. Journal of Telemedicine and Telecare, 22(5), 282-295. https:// doi.org/10.1177/1357633X15600583

De Simone, V., Guarise, P., Guardalben, S., Padovani, N., Tondelli, S., Sandrini, D., Visentin, E., \& Zanotto, G. (2020). Telecardiology during the Covid-19 pandemic: past mistakes and future hopes. American Journal of

Cardiovascular Disease, 10(2), 34-47.

http://www.ncbi.nlm.nih.gov/

pubmed/32685262

Dendale, P., De Keulenaer, G., Troisfontaines, P., Weytjens, C., Mullens, W., Elegeert, I., Ector, B., Houbrechts, M., Willekens, K., \& Hansen, D. (2012). Effect of a telemonitoring-facilitated

collaboration between general practitioner and heart failure clinic on mortality and rehospitalization rates in severe heart failure: the TEMA-HF 1 (TElemonitoring in the MAnagement of Heart Failure) study. European Journal of Heart Failure, 14(3), 333-340.https://doi.org/10.1093/eurjhf/ hfr144

Frederix, I., Vanderlinden, L., Verboven, A.-S., Welten, M., Wouters, D., De Keulenaer, G., Ector, B., Elegeert, I., Troisfontaines, P., Weytjens, C., Mullens, W., \& Dendale, P. (2019). Long-term impact of a six-month telemedical care programme on mortality, heart failure readmissions and healthcare costs in patients with chronic heart failure. Journal of Telemedicine and Telecare, 25(5), 286293.

10.1177/1357633X18774632

https://doi.org/

Gensini, G. F., Alderighi, C., Rasoini, R., Mazzanti, M., \& Casolo, G. (2017). Value of Telemonitoring and Telemedicine in Heart Failure Management. Cardiac Failure Review, 3(2), 1. https://doi.org/10.15420/cfr. 2017:6:2

Greenhalgh, T., A'Court, C., \& Shaw, S. (2017). Understanding heart failure; explaining telehealth - a hermeneutic systematic review. BMC Cardiovascular Disorders, 17(1), 156. https://doi.org/10.1186/s12872-0170594-2

Higgins, J. P., \& Altman, D. G. (2008). Assessing Risk of Bias in Included Studies. In J. P. Higgins \& S. Green 
(Eds.), Cochrane Handbook for Systematic Reviews of Interventions (pp. 187-241). John Wiley \& Sons, Ltd. https://doi.org/ 10.1002/9780470712184.ch8

Knox, L., Rahman, R. J., \& Beedie, C. (2017). Quality of life in patients receiving telemedicine enhanced chronic heart failure disease management: A meta-analysis. Journal of Telemedicine and Telecare, 23(7), 639$649 . \quad$ https://doi.org/ 10.1177/1357633X16660418

Kotb, A., Cameron, C., Hsieh, S., \& Wells, G. (2015). Comparative Effectiveness of Different Forms of Telemedicine for Individuals with Heart Failure (HF): A Systematic Review and Network Meta-Analysis. PLOS ONE, 10(2), e0118681. https://doi.org/10.1371/ journal.pone.0118681

Ramaekers, B. L. T., Janssen-Boyne, J. J., Gorgels, A. P. M., \& Vrijhoef, H. J. M. (2009). Adherence Among Telemonitored Patients with Heart Failure to Pharmacological and Nonpharmacological

Recommendations. Telemedicine and EHealth, 15(6), 517-524. https://doi.org/ 10.1089/tmj.2009.0160

Riley, W. T., Keberlein, P., Sorenson, G., Mohler, S., Tye, B., Ramirez, A. S., \& Carroll, M. (2015). Program Evaluation of Remote Heart Failure Monitoring: Healthcare Utilization Analysis in a Rural Regional Medical Center. Telemedicine and E-Health, 21(3), 157-162. https://doi.org/10.1089/ tmj.2014.0093
Roth, A., Kajiloti, I., Elkayam, I., Sander, J., Kehati, M., \& Golovner, M. (2004). Telecardiology for patients with chronic heart failure: the 'SHL' experience in Israel. International Journal of Cardiology, 97(1), 49-55. https://doi.org/10.1016/j.ijcard. 2003.07.030

Savard, L. A., Thompson, D. R., \& Clark, A. M. (2011). A meta-review of evidence on heart failure disease management programs: the challenges of describing and synthesizing evidence on complex interventions. Trials, 12(1), 194. https:// doi.org/10.1186/1745-6215-12-194

Savarese, G., \& Lund, L. H. (2017). Global Public Health Burden of Heart Failure. Cardiac Failure Review, 03(01), $7 . \quad$ https://doi.org/10.15420/cfr. 2016:25:2

Spaeder, J., Najjar, S. S., Gerstenblith, G., Hefter, G., Kern, L., Palmer, J. G., Gottlieb, S. H., \& Kasper, E. K. (2006). Rapid titration of carvedilol in patients with congestive heart failure: A randomized trial of automated telemedicine versus frequent outpatient clinic visits. American Heart Journal, 151(4), 844.e1-844.e10. https:// doi.org/10.1016/j.ahj.2005.06.044

Zhu, Y., Gu, X., \& Xu, C. (2020). Effectiveness of telemedicine systems for adults with heart failure: a metaanalysis of randomized controlled trials. Heart Failure Reviews, 25(2), 231243. https://doi.org/10.1007/s10741019-09801-5 